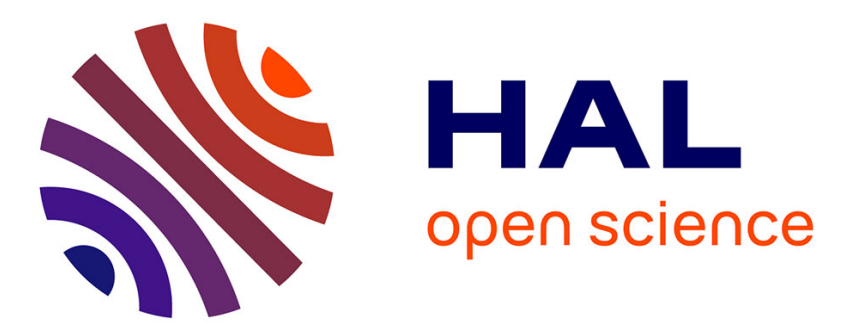

\title{
Plane-compression properties of microcellular injected polypropylene using gas counter pressure and core-back expansion process
}

\author{
José Antonio Reglero Ruiz, Michel Vincent, Noëlle Billon
}

\section{- To cite this version:}

José Antonio Reglero Ruiz, Michel Vincent, Noëlle Billon. Plane-compression properties of microcellular injected polypropylene using gas counter pressure and core-back expansion process. International Journal of Material Forming, 2016, 9 (5), pp.585-590. 10.1007/s12289-015-1244-9 . hal-01178876

HAL Id: hal-01178876

https://hal-mines-paristech.archives-ouvertes.fr/hal-01178876

Submitted on 21 Oct 2015

HAL is a multi-disciplinary open access archive for the deposit and dissemination of scientific research documents, whether they are published or not. The documents may come from teaching and research institutions in France or abroad, or from public or private research centers.
L'archive ouverte pluridisciplinaire HAL, est destinée au dépôt et à la diffusion de documents scientifiques de niveau recherche, publiés ou non, émanant des établissements d'enseignement et de recherche français ou étrangers, des laboratoires publics ou privés. 


\title{
Plane-Compression properties of microcellular injected polypropylene using gas counter pressure and core-back expansion process
}

\author{
José Antonio Reglero Ruiz, Michel Vincent, Noëlle Billon \\ ${ }^{1}$ MINES ParisTech - Centre de Mise en Forme des Matériaux (CEMEF) \\ UMR CNRS 7635 \\ 1, Rue Claude Daunesse, CS 10207, 06904 - Sophia Antipolis Cedex, France.
}

Keywords: microcellular injection molding, chemical blowing agents, polypropylene, mechanical properties

\begin{abstract}
Microcellular Polypropylene (PP) was obtained using Chemical Blowing Agents (CBA) in a injection process combined with Gas Counter Pressure (GCP) and core-back expansion molding. Two different types of $P P$, neat and charged, were mixed with a fixed proportion of CBA and injected into a plate, obtaining structural foams with a foamed core and solid outer skins. After, the plate morphology is analyzed to evaluate the main morphological parameters, such as cell size and thickness of the outer skin. The results show that the type of CBA has a great influence on the cell size. Finally, low velocity plane compression tests were carried out in the structural foams at a fixed strain rate to obtain the Young's modulus of the foamed core and also the whole structure, using some theoretical approaches to evaluate the effect of foam density in the obtained results.
\end{abstract}




\section{1 - INTRODUCTION}

The commercial and industrial interest in polymeric structural foams has been increasing in the last years, due to the combination of good mechanical properties together with weight reduction. Especially in injection molded parts, the foaming process provides several advantages, such as good surface aspect, good dimensional stability and the reduction of the raw material costs [1]. The injection foaming process leads to core-shell foamed structures with closed outer skins and a foamed core [2,3]. This allows obtaining equivalent mechanical properties to a neat polymer injected part, but with a weight reduction.

One of the main injection processes is based on using chemical blowing agents (CBA) $[4,5,6]$. The foaming agent is added in the form of pellets to the feeder of the injection machine, in a proportion between 1 and $2 \%$ in weight. The foaming agent usually is a low density polyethylene charged with a percentage of inorganic compounds, such as citric acid or sodium bicarbonate, which decompose at temperatures close to the melting point of the polymer, generating the gas, mainly $\mathrm{CO}_{2}$ and water vapor.

The core-back expansion process which is investigated in this paper derives from the classical injection molding process, where a command module is added to control the movement of the mobile part of the mold. Once the polymer containing a foaming gas fills up the mold, the mold is accurately opened to quickly increase the cavity volume and rapidly reduce pressure. The sudden pressure drop enhances bubble nucleation and achieves a fine cell structure within the polymer foam. Thus, core-back foam injection molding is effective in achieving a high expansion ratio with uniform fine cell structure. Moreover, compared to classical microcellular injection processes, the core-back foam injection molding process allows increasing the thickness of the final part, thus reducing the foam density.

Although microcellular injection molding process has many advantages, the resulting products usually have severe surface defects such as swirl marks and lack of smoothness $[7,8]$. The introduction of a gas counter pressure (GCP) in microcellular injection molding process has been recently analyzed to improve the surface quality of molded parts, because it can prevent the foaming reaction in the front flow during injection step [9,10]. In all these studies, the efficiency of the introduction of the GCP has been demonstrated to reduce the surface defects drastically when microcellular foaming process is employed.

The present work is focused on the analysis of the mechanical properties of the structural foams obtained using this process. Plane compression tests have been carried out, to obtain the Young's modulus of the foamed core. After, a theoretical approach has been used to estimate the Young's modulus of the whole sample, including both the core and the solid outer skin. The influence of several parameters, such as cell size and foam density has been also investigated. The foamed core density has revealed as the most important parameter to determine the mechanical properties, with a small influence of the cell size. The results obtained show an interesting way to estimate the Young's modulus in compression tests of the foamed core, without removing the solid skin. Moreover, simple models have been employed to predict the mechanical properties of these materials. 


\section{2 - MATERIALS AND EXPERIMENTAL PROCEDURES}

\section{1 - Raw Materials}

A pure polypropylene (PP) with a melt flow index of $65 \mathrm{~g} / 10 \mathrm{~min}$ (ISO R1133), and a density of $0.91 \mathrm{~g} / \mathrm{cm}^{3}$ was employed in all the experiments. Two different endothermic chemical blowing agents referred as CBA-1 and CBA-2 have been used [11]. These foaming agents are PE-based compounds with reactive elements (citric acid, sodium bicarbonate or a mix of both components). CBA-1 contains 70 wt. \% of citric acid and CBA-2 contains 70 wt. \% of sodium bicarbonate, (wt. \% respect to PE matrix). In the following, CBA refers to the compound and not to the reactive elements only.

\section{2 - Injection tests}

Injection tests were carried out using an ENGEL machine, with a maximal injection capacity of $150 \mathrm{~cm}^{3}$. It is equipped with a shut-off nozzle. The screw diameter $D$ was $32 \mathrm{~mm}$, with $L / D$ $=24$ ( $L$ is the screw length). Polymer pellets were introduced in the barrel with $2 \mathrm{wt} . \%$ of $\mathrm{CBA}$, and melted at temperatures that can reach $230^{\circ} \mathrm{C}$. Mold temperature was fixed to 40 ${ }^{\circ} \mathrm{C}$. A back pressure is applied at the plasticization unit which values between 6 and $8 \mathrm{MPa}$. The residence time of the CBA-PP system before injection shot is about 6 minutes. The decomposition reaction of the CBA produces both $\mathrm{CO}_{2}$ and $\mathrm{H}_{2} \mathrm{O}$ vapor, which is expected that after foaming and cooling of the samples remains as condensed water vapor. Then the polymer and the dissolved gas $\left(\mathrm{CO}_{2}+\mathrm{H}_{2} \mathrm{O}\right.$ vapor $)$ are injected into the mold. A gas counter pressure (GCP) is applied in the cavity during the filling step to prevent the development of the foaming reaction. In a second step, the mobile part of the mold moves backwards slightly. This movement causes a rapid pressure decrease in the cavity so that it allows the blowing agent to expand and to create a cellular structure in the core of the injected part. No other injection parameters were varied (injection temperature, flow rate or core-back opening course).

Rectangular plates were molded. The final thickness of the sample is $2.5 \mathrm{~mm}$ after foaming. The total volume of the sample including sprue and gate was about $36 \mathrm{~cm}^{3}$, with a weight of $25 \mathrm{~g}$. The mold temperature was fixed at $40^{\circ} \mathrm{C}$. The injection temperature was $230^{\circ} \mathrm{C}$. Gas Counter Pressure was fixed to $15 \mathrm{bar}$, using nitrogen gas, connecting the mold to a highpressure $\mathrm{N}_{2}$ system using and automatic valve. Two groups of samples were injected using different CBA's. A total number of 15 plates was injected in each group. A minimum of three plates of each test were analyzed to assure a good reproducibility of the morphology results. For the mechanical tests, five plates of each group were analyzed. Figure 1 presents a scheme of the core-back expansion molding process.

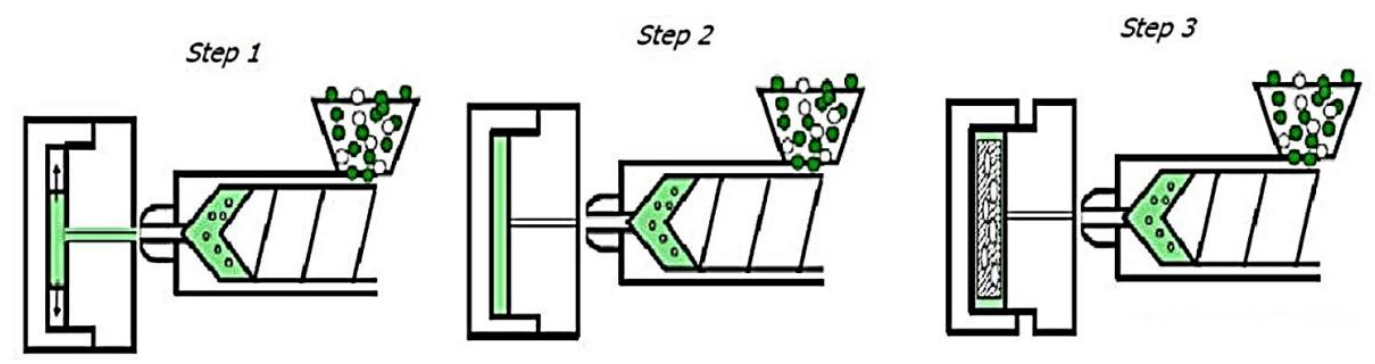

Figure 1 - Core-back expansion molding process. 


\section{3 - Morphological characterization}

Scanning Electron Microscopy images (SEM) were taking using a Philips equipment (Model Philips XL-30). For the morphological observations, samples were fractured at ambient temperature, to assure a good contrast between solid and foamed regions. All the observations were carried out extracting three samples from the center of the plate, in the perpendicular direction to the injection flow.

The morphological parameters were quantified using the ImageJ® software [11]. This software accounts for the number of bubbles in each image and the average radius. Cell density $N_{c}$ in the sample was calculated using equation (1) [12], which accounts for the 3D extrapolation starting from a 2D image:

$$
N_{c}=\frac{6\left(1-\frac{\rho_{F}}{\rho_{P}}\right)}{\pi R^{3}} V_{f}
$$

$\rho_{F}$ represents the foam core density, and $\rho_{P}$ the solid polymer density $\left(0.91 \mathrm{~g} / \mathrm{cm}^{3}\right) . V_{f}$ represents the volume of each extracted sample, in our case $2.5 \times 10 \times 10 \mathrm{~mm}^{3}$. The average radius $\bar{R}$ is calculated from equation (2):

$$
\bar{R}=\frac{\sum_{i=1}^{N} n_{i} R_{i}}{\sum_{i=1}^{N} n_{i}}
$$

, where $N$ represents the bubble count. The minimum quantifiable bubble radius is $1 \mu \mathrm{m}$, and a three different morphological observations were determined using this software to minimize the deviation derived from the extrapolation from 2D to 3D. The software calculates for each bubble $i$ the radius $R_{i}$, assuming that each bubble is a sphere, which is a first approximation. Then, it calculates the average bubble radius $\bar{R}$ of the foamed core in the micrograph by using equation (2). Other geometrical approximations can be taken into account (for example, ellipsoids), but considering spherical-shape bubbles was found to be the most accurate calculation.

\section{4 - Plane-Compression tests}

Low velocity plane compression tests were carried out in five samples extracted of each plate, with dimensions $2.5 \times 10 \times 10 \mathrm{~mm}^{3}$, at a strain rate of $0.4 \mathrm{~s}^{-1}$ and at room temperature. The external edges of the samples were cut to avoid side effects due to injection skin. Samples were tested using an INSTRON type machine, with a $10 \mathrm{KN}$ load cell, up to $75 \%$ of stress, reaching the densification area. Young's modulus was calculated by fitting the initial linear part of the strain-stress curve of each sample. All the results of the five samples were averaged.

\section{3 - RESULTS AND DISCUSSION}

\section{1 - Morphology}

Figure 2 illustrates the morphology of the structural foamed samples. First, it is clear that using CBA-1, based on citric acid, leads to lower cell sizes than using CBA-2, which is based on sodium bicarbonate. It is observed also that both samples present an homogeneous 
structure, with a solid outer skin with total thickness about $700 \mu \mathrm{m}$. The density values of the foamed core of the samples varied between $0.49 \mathrm{~g} / \mathrm{cm}^{3}$ and $0.71 \mathrm{~g} / \mathrm{cm}^{3}$. In our work, samples obtained with CBA-2 presented lower density values. It was observed that the solid outer skin total thickness did not vary because the mold temperature was fixed in all the injection tests. Moreover, the foamed core density presents a very small variation because is directly related to the course during core-back opening, which was also fixed in all the experiments. li is expected that varying the core-back displacement has a direct influence in the microcellular density.
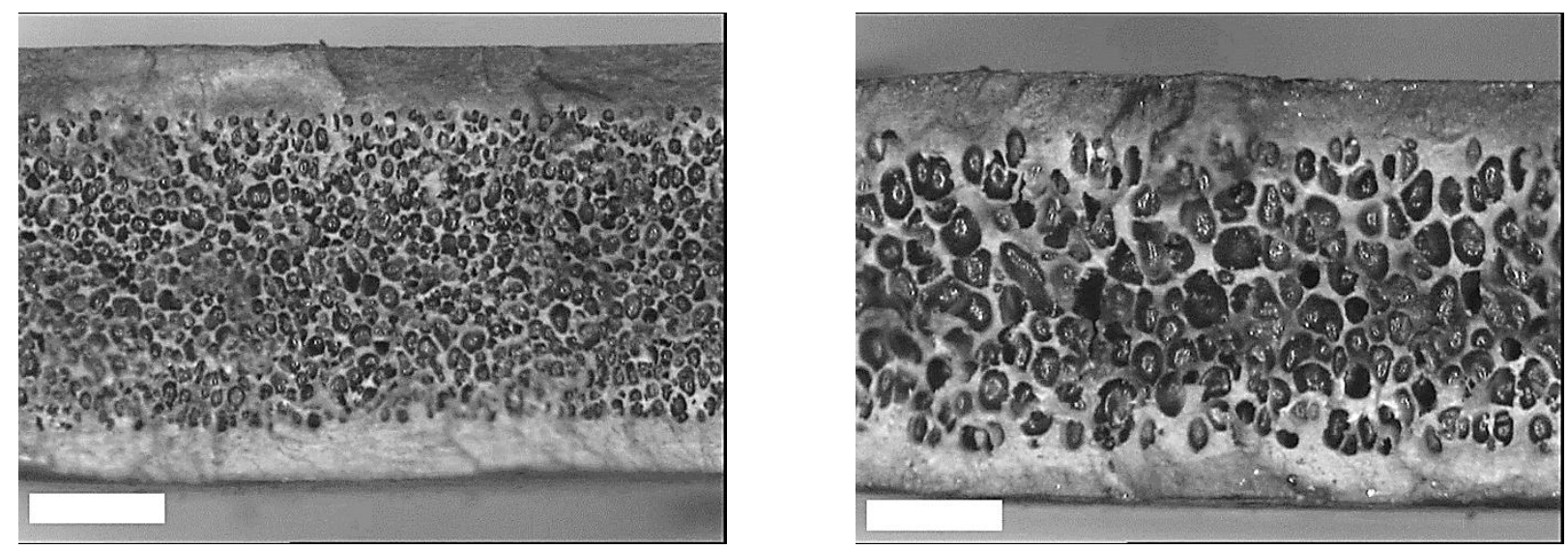

Figure 2-SEM micrographs showing the morphology of the structural foamed samples (bar scale $1 \mathrm{~mm}$ )
a) $\mathrm{PP}+\mathrm{CBA}-1$
b) $P P+C B A-2$

The morphological parameters obtained using the ImageJ® software are presented in table 1.

\begin{tabular}{|c|c|c|c|c|c|}
\hline CBA & $\begin{array}{c}\bar{R} \\
(\mu \mathrm{m})\end{array}$ & $\begin{array}{c}\text { Bubble } \\
\text { count }\end{array}$ & $\begin{array}{c}\text { Solid skin } \\
\text { thickness } \\
(\mu \mathrm{m})\end{array}$ & $\begin{array}{c}\mathbf{N}_{c} \\
\left(\mathrm{~cm}^{-3}\right)\end{array}$ & $\begin{array}{c}\rho_{f} \\
\left(\mathbf{g} / \mathbf{c m}^{3}\right)\end{array}$ \\
\hline 1 & $41 \pm 6$ & 314 & $700 \pm 20$ & $1.44 \cdot 10^{5}$ & $0.56-0.71$ \\
\hline 2 & $74 \pm 11$ & 128 & $715 \pm 10$ & $3.21 \cdot 10^{4}$ & $0.49-0.53$ \\
\hline
\end{tabular}

Table 1-Morphological parameters of the injected PP samples.

\subsection{Plane-compression tests}

Figure 3 presents an example of a strain-stress $(\sigma, \varepsilon)$ curve obtained from the plane compression test. This curve corresponds to a typical stress-strain curve of a cellular material [13]. There are 4 regions clearly defined. Region 1 corresponds to the elastic regime of the material, and it is employed to obtain the elastic Young's modulus. The region number 2 is defined by the yield stress $\sigma_{y}$, and corresponds to the Plateau regime, and it is related to the energy absorption capability of the material. In an ideal cellular material, $\sigma_{y}=\sigma_{p}$. In the region number 3 , an important quantity of the gas inside the bubble escapes due to buckling and rupture of the cell walls, leading to a densification regime in which strain increases greatly. Finally, in region 4 there is no gas remaining in the cells, and the polymer presents a 
compression behavior similar to a solid. In figure $3, \sigma_{D}$ and $\varepsilon_{D}$ represent the stress and strain at which densification process begins. In an ideal behaviour, the slope of the stress-strain curve in the plateau region is null, and no decrease of the slope is produced at the beginning of the densification region. However, in real samples, this small change in the slope can be produced due to inhomogeneities of the cellular structure

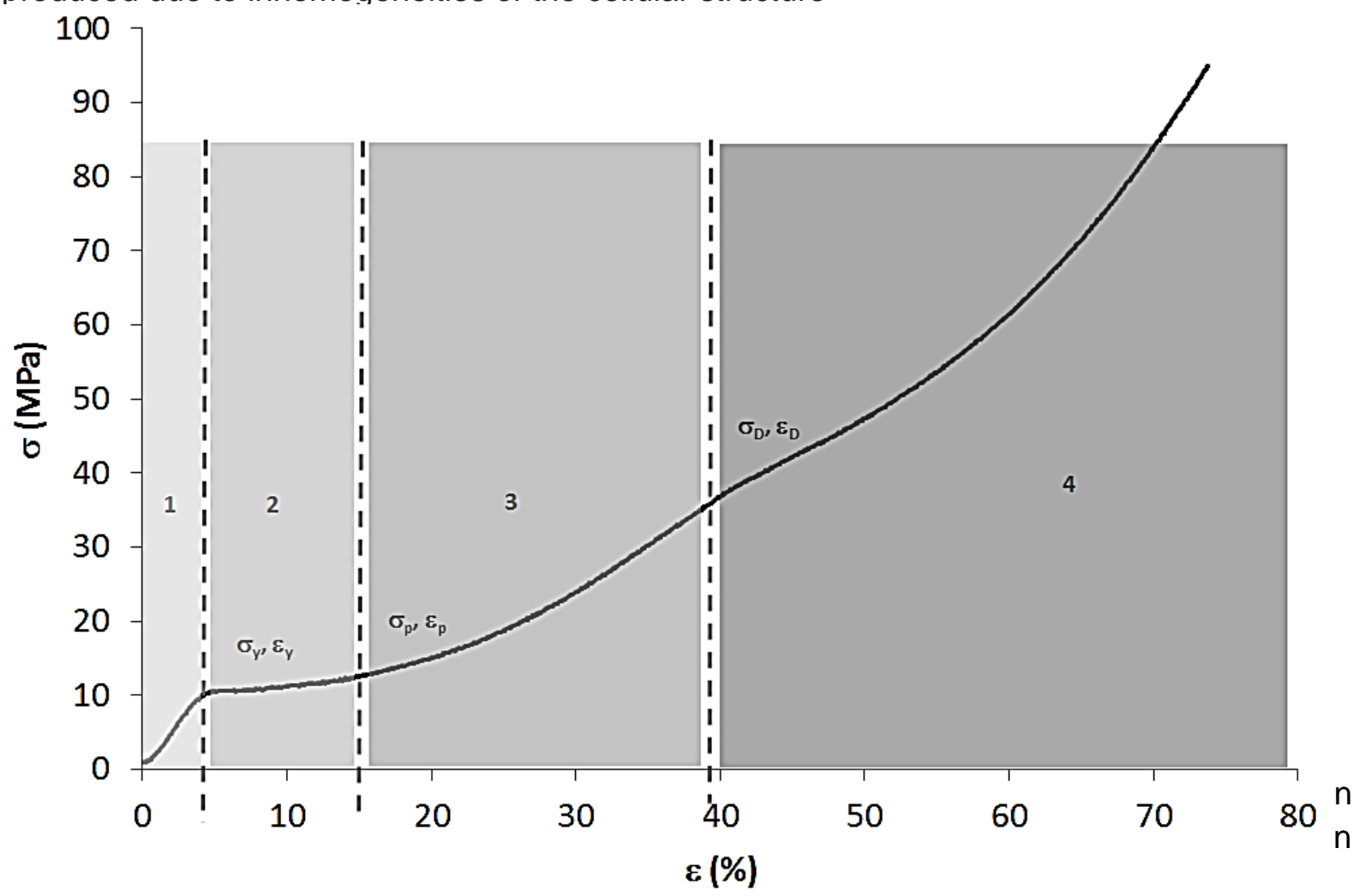

\begin{tabular}{|c|c|c|c|c|}
\hline CBA & $\begin{array}{c}E_{f} \\
(\mathrm{MPa})\end{array}$ & $\begin{array}{c}\sigma_{y} \\
(\mathrm{MPa})\end{array}$ & $\begin{array}{c}\varepsilon_{D} \\
(\%)\end{array}$ & $\begin{array}{c}\rho_{f} \\
\left(\mathrm{~g} / \mathbf{c m}^{3}\right)\end{array}$ \\
\hline 1 & $222 \pm 11$ & $10.6 \pm 0.6$ & $41 \pm 6$ & $0.56-0.71$ \\
\hline 2 & $204 \pm 8$ & $9.1 \pm 0.5$ & $38 \pm 4$ & $0.49-0.53$ \\
\hline
\end{tabular}

Table 2 - Mechanical properties of the microcellular injected PP samples.

Values of Young's modulus $E_{f}$ vary between $204 \mathrm{MPa}$ and $222 \mathrm{MPa}$, about $10 \%$ of the value obtained for the solid PP $\left(E_{s}=2.2 \mathrm{GPa}\right)$. This value corresponds to a high-impact resistance polypropylene, and was obtained experimentally and provided by the raw material supplier. The elastic limit strain $\varepsilon_{y}$ employed to calculate the values of Young's modulus was about $5 \%$ in all the cases. Some mechanical tests were employed to validate this limit, and after testing only up to the linear regime, samples recovered their initial thickness. On the other hand, densification strain values $\varepsilon_{y}$ are in the range of $40 \%$. This is a low value compared to low density polyolefin foams [14] which present a higher value of the densification strain (75\%), making them suitable for energy absorbing applications. It was observed that during the plane compression tests, the foamed core was compressed while the solid outer skin can be considered as an additional compression plate, and has no influence in the mechanical 
properties measured. Thus, the Young's modulus measured during compression tests corresponded only to the foamed core.

A semi empirical expression relating the Young's modulus of cellular materials with the Young's modulus of the solid polymer is given by Gibson and Ashby [13]:

$$
\frac{E_{f}}{E_{s}}=C\left(\frac{\rho_{f}}{\rho_{s}}\right)^{n}
$$

$E_{f}$ is the Young's modulus of the cellular material, $E_{S}$ is the Young's modulus of the solid material, $\rho_{f}$ is the foam density and $\rho_{s}$ is the solid polymer density.

The values of $E_{S}(2.2 \mathrm{GPa})$ and $\rho_{S}\left(0.91 \mathrm{~g} / \mathrm{cm}^{3}\right)$ are known. It is possible to plot the relative Young's modulus versus the relative foam density to determine the parameters $C$ and $n$. The results are presented in figure 4 , for all the experimental samples obtained, in a log-log graph, together with the theoretical correlation to determine $\mathrm{C}$ and $\mathrm{n}$.

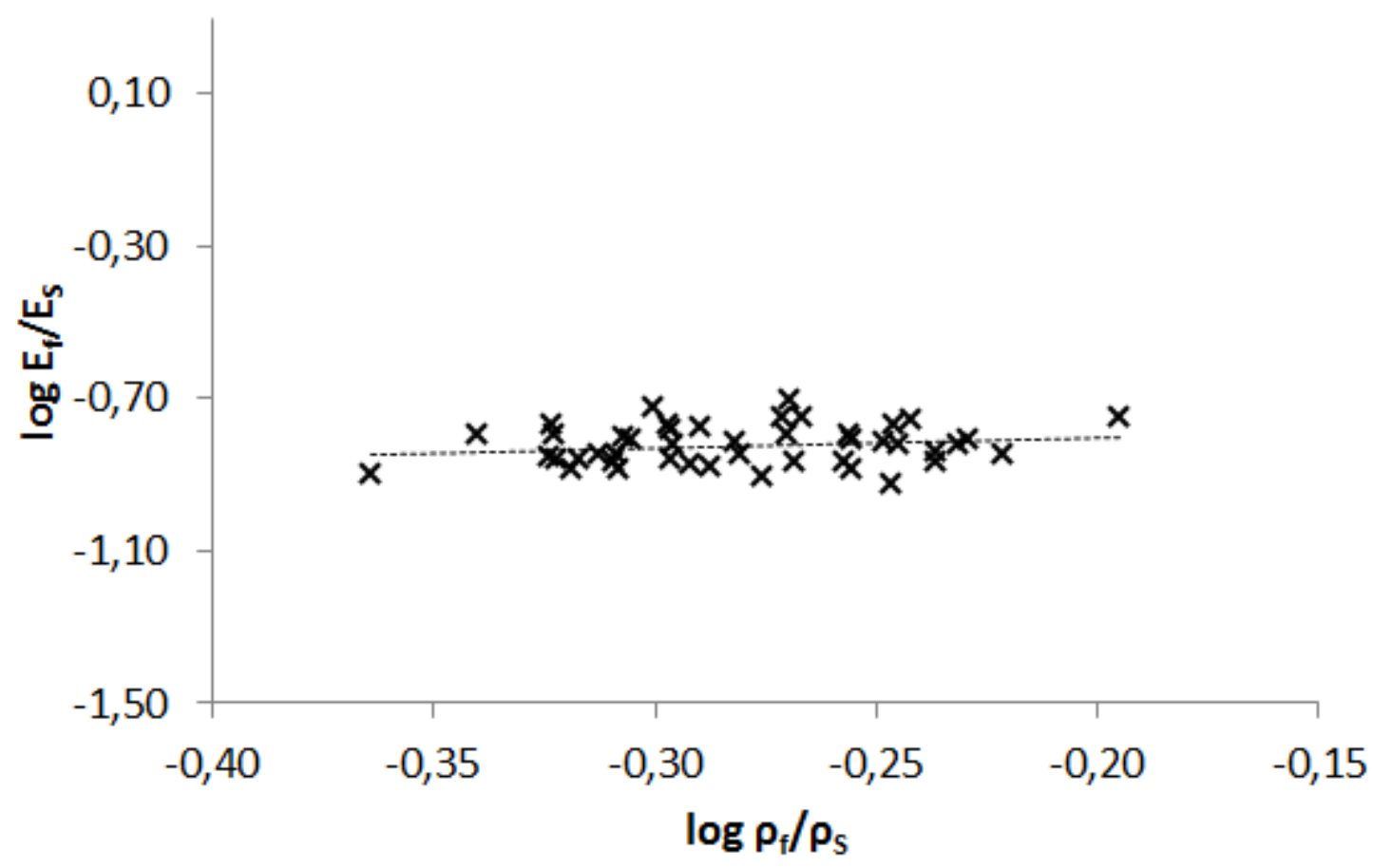

Figure 4 - Relation between relative young's modulus and relative density (Equation 3)

The obtained values for $C$ and $n$ are 0.1754 and 0.4493 , res

pectively, with a correlation factor $r^{2}$ of 0.98343 . Although the correlation can be considered correct, the values of $n$ are lower than expected (literature values are between 1 and 2), probably because the range of density analyzed in this work is narrow [13]. However, as explained before, the range of density values was directly related to core-back opening course, and this parameter could not be varied during all the tests.

The Young's modulus of the whole structural material can be obtained using the next expression [15], considering a mixing law in which the core and solid skin are placed in a series arrangement: 


$$
\frac{1}{E_{e}}=\left(2 t_{s}+t_{f}\right) \cdot\left[\frac{1}{2 t_{s} E_{s}}+\frac{1}{t_{f} E_{f}}\right]
$$

, where $E_{e}$ corresponds to the Young's modulus of the structural material (foamed core + solid skin), and $E_{S}$ and $E_{f}$ are the Young's modulus of the solid skin and the foamed core. In addition, $t_{s}$ is the half thickness of the solid skin, and $t_{f}$ is the total thickness of the foamed core. Thicknesses of the solid outer skin and foamed core are obtained directly from the SEM images presented in figure 2.

Table 3 shows the average results obtained in both groups of samples, when applying equation (4).

\begin{tabular}{|c|c|c|c|c|c|}
\hline Group & CBA & $\begin{array}{c}\boldsymbol{t}_{\boldsymbol{s}} \\
(\boldsymbol{\mu \mathrm { m }})\end{array}$ & $\begin{array}{c}\boldsymbol{t}_{\boldsymbol{f}} \\
(\boldsymbol{\mu \mathrm { m }})\end{array}$ & $\begin{array}{c}\boldsymbol{E}_{\mathrm{f}} \\
(\mathrm{MPa})\end{array}$ & $\begin{array}{c}\boldsymbol{E}_{\boldsymbol{e}} \\
(\mathrm{MPa})\end{array}$ \\
\hline 1 & 1 & $350 \pm 20$ & $1800 \pm 40$ & $345 \pm 11$ & $1343 \pm 48$ \\
\hline 2 & 2 & $367 \pm 10$ & $1734 \pm 20$ & $284 \pm 8$ & $1321 \pm 39$ \\
\hline
\end{tabular}

Table 3 - Values of the Young's modulus of the PP structural foam samples obtained from equation 4.

As seen in table 3, the results obtained for the Young's modulus of the structural foam are in the range of $1.3 \mathrm{GPa}$, with no variations between both groups. This value is about $35 \%$ lower than the Young's modulus of the solid material ( $\left.E_{s}=2.2 \mathrm{GPa}\right)$.

To summarize, the mechanical properties of the structural foams depend strongly on the density, and as expected, Young's modulus is increased with foamed core density. On the other hand, cell size does not have a great influence in the mechanical parameters measured. In our work, values of the Young's modulus are increased only a $10 \%$ when cell radius is reduced about $100 \%$ (see values of tables 1 and 2). However, it is known that reducing drastically the cell size up to sub-micrometrical or nanometrical sizes has a great influence in the mechanical properties, especially in the Young's modulus [16].

The final density of the samples does not vary significantly, indicating that the quantity of gas dissolved during the plasticization process remains constant during all tests. The thickness of the structural foamed samples does not present great variations, because is mainly controlled by the injection parameters that have been unchanged in this work. Only the average cell size is mainly controlled by the type CBA employed. When employing citric acid CBA cell sizes are drastically reduced, but no great impact in the mechanical properties is observed.

\section{4- CONCLUSIONS}

In this work, the mechanical and morphological aspects of microcellular injected PP plates using Gas Counter Pressure (GCP) and core-back have been analyzed. Two different Chemical Blowing Agents (CBA) were employed, with a fixed proportion of $2 \%$ wt. and analyzing the morphological parameters and compression Young's modulus of the obtained samples. 
Structural foamed samples obtained presented a homogeneous cellular structure, with similar values of density (about $0.5 \mathrm{~g} / \mathrm{cm}^{3}$ ) and thickness of the solid outer skin, indicating that both aspects are dependent on the injection conditions. However, the average cell size depended strongly on the type of CBA employed, and using a citric acid based CBA leads to a significant reduction in the cell size compared to the cellular structure obtained when using sodium bicarbonate-based CBA.

Concerning the mechanical properties, a set of low velocity plane compression tests were investigated. The values of the Young's modulus of the foamed core were between $200 \mathrm{MPa}$, about ten times lower than solid polymer, with a good reproducibility of the results. A theoretical approach was also used, which allows obtaining the Young's modulus of the whole structural foamed samples, which values in the range of $1 \mathrm{GPa}$, about five times higher than the values found for the foamed core.

\section{ACKNOWLEDGMENTS}

Authors would like to acknowledge SUMIKA Polymer Compounds France for providing the raw materials, and also to Aurore Claverie and Sebastien Huck (MECAPLAST France), for producing the injected plates. Financial support FUI (PLUME Project, France) is also gratefully acknowledged.

\section{REFERENCES}

1. Xu J, Turng LS (2010) Microcellular injection molding, Wiley International.

2. Mechraoui A, Riedl B, Rodrigue D (2011) Mechanical properties of polypropylene structural foams with fiber-reinforced skins. Journal of Cellular Plastics 47(2):115-132

3. Reglero Ruiz JA, Pedros M, Tallon JM, Dumon M (2011) Micro and nano cellular amorphous polymers (PMMA,PS) in supercritical $\mathrm{CO}_{2}$ assisted by nanostructured $\mathrm{CO}_{2}$-philic block copolymers - one step foaming process. Journal of Supercritical Fluids 58(1):168-176

4. Behravesh AH, Park CB, Cheung LK, Venter RD (1996) Extrusion of polypropylene foams with hydrocerol and isopentane. Journal of Vinyl \& Additive Technology. 2(4):349-357

5. Bociaga E, Palutkiewicz P (2013) The influence of injection molding parameters and blowing agent addition on selected properties, surface state and structure of HDPE parts. Polymer Engineering and Science 53(4):780-791

6. Bledzki AK, Faruk O (2005) Effects of the chemical foaming agents, injection parameters and melt-flow index on the microstructure and mechanical properties of microcellular injection-molded wood-fiber/polypropylene composites Journal of Applied Polymer Science, 97(3):1090-1096

7. Cha SW., and Yoon JD.: Microcellular injection molding with improved surface quality. Polymer Plastic Technology Engineering, 44:1-4, 2005.

8. Guo MC, Santoni A, Heuzey MC, Carreau PJ (2007) Ocurrence of surface defects in TPO. Injected foam parts. Journal. of Cellular Plastics. 43(4-5):273-296 
9. Lee J, Turng LS, Dougherty E, Gorton P (2011) A novel method for improving the surface quality of microcellular injection molded parts. Polymer, 52(6):1436-1446

10. Turng LS, Kharbas H (2004) Development of a hybrid solid-microcellular co-injection molding process. International Polymer Processing, 19(1):77-86

11. Reglero Ruiz JA, Vincent M, Agassant JF, Sadik T, Pillon C, Carrot C (2014): Polymer foaming with chemical blowing agents: experiment and modeling. Polymer Engineering and Science, doi: $10.1002 /$ pen.24044

12. Gosselin R, Rodrigue D (2005) Cell morphology analysis of high density polymer foams. Polymer testing, 24(8):1027-1035

13. Gibson LJ, Ashby MF (1999) Cellular solids: structure and properties, Cambridge solid state science series

14. Rodriguez-Perez, MA, Velasco JI, Arencon D, Almanza O, De Saja JA (2000) Mechanical properties of closed cell polyolefin foams. Journal of Applied Polymer Science, 75(1):156-166

15. Fleck, NA, Sridhar I (2002) End compression of sandwich columns. Composites: part A, 33:353-359

16. Reglero Ruiz, JA, Viot P, Dumon, M (2009) Foaming behaviour and compressive properties of microcellular nanostructured polystyrene. Cellular Polymers, 28(6):363-385 